Meta

Journal des traducteurs

Translators' Journal

\title{
An Integrated Perspective on Cognitive Strategies in Language Processing
}

Gary D. Prideaux et William J. Baker

Volume 29, numéro 1, mars 1984

Cerveau, langage et traduction

URI : https://id.erudit.org/iderudit/003869ar

DOI : https://doi.org/10.7202/003869ar

Aller au sommaire du numéro

Éditeur(s)

Les Presses de l'Université de Montréal

ISSN

0026-0452 (imprimé)

1492-1421 (numérique)

Découvrir la revue

Citer cet article

Prideaux, G. D. \& Baker, W. J. (1984). An Integrated Perspective on Cognitive

Strategies in Language Processing. Meta, 29(1), 81-90.

https://doi.org/10.7202/003869ar d'utilisation que vous pouvez consulter en ligne.

https://apropos.erudit.org/fr/usagers/politique-dutilisation/ 


\title{
AN INTEGRATED PERSPECTIVE ON COGNITIVE STRATEGIES IN LANGUAGE PROCESSING*
}

\author{
Gary D. Prideaux and William J. Baker
}

\begin{abstract}
When comprehending language, the hearer constantly constructs internal representations for the meanings of the sentences he encounters. He utilizes all available information, including his knowledge of the world, knowledge of his language structure, meaning, rules of conversation and discourse, and the like. As Slobin $(1979$, p. 53) points out, since no one of these factors is in itself sufficient for the job, the hearer employs as many resources as necessary as he actively constructs meaning representations. Over the past decade or so, psycholinguists have come to realize that there is far more to language comprehension and acquisition than was suggested by various versions of the "derivational theory of complexity" (see, e.g., Fodor, Bever \& Garrett : 1974, Ch. 6 for a review of this issue). As a result, much research has shifted toward a formulation and evaluation of those "perceptual" or "cognitive" or "mental" strategies used by hearers engaged in the process of language comprehension, and many strategies have been proposed to account for the complexities manifest in language acquisition. Research dealing with cognitive strategies relative to language seems to have had its most recent instigation with Bever and his colleagues (cf. Bever 1970a, 1970b; Slobin 1970). Bever (1970a) proposed a number of strategies, with supporting evidence for each, and other researchers have continued to explore Bever's proposals, adding further evidence or suggesting alternatives. In short, the notion of cognitive strategies has played an active role in both language processing and language acquisition research over the past decade or so.

While strategies proposed in the literature often appear individually plausible, they frequently seem to bear little relation either to each other or to any integrated view of mental processing. Some proposed strategies, for example, are semantically based, while others are basically syntactically motivated parsing schemes. Similarly, certain strategies are definitely language specific, while others tend to be language independant, and possibly universal. When the issue of the organization of the strategies in terms of a coherent framework arises, however, there are still many areas of ambiguity, if not downright contradiction. An overall, internally consistent theory of language use has yet to be formulated.

One area of serious confusion lies in the relationship between a grammar and a set of strategies. Slobin (1970 p. 175), for example, states "We approach grammar as a set of linguistic strategies used to express various semantic relationships in spoken utterances." This suggests that a grammar is to be understood as a set of linguistic strategies, a view shared by Lakoff and Thompson (1975 p. 295), who stated :
\end{abstract}

* This research was supported in part by Social Sciences and Humanities Research Council of Canada Grants 410-80-0343 and 410-82-0153. 
...GRAMMARS ARE JUST COLLECTIONS OF STRATEGIES FOR UNDERSTANDING AND PRODUCING SENTENCES. From this point of view, abstract grammars do not have any separate mental reality : they are just convenient fictions for representing certain processing strategies (original emphasis).

Presumably, Lakoff and Thompson are inveighing against generative transformational grammars when they speak of "abstract grammars". However, just because a transformational grammar has no "separate mental reality" does not mean that grammars and strategies are one and the same thing.

In the present work, a sharp distinction is drawn between a grammar and a strategy. In particular, a grammar is understood here as a description of those (normally language-specific) linguistic devices which are used to relate various types of syntactic form to linguistic information. For example, a rule of English states that the function to be assigned to that NP to the left of the main verb, as in "Has Sam already left ?", is "subject" unless the sentence has no object NP, in which case the subject NP can follow the main verb, as in "In strolled old Sam". It is important to distinguish a static rule of grammar from those procedural rules which speakers and hearers use when actually speaking or comprehending their language.

Thus, a strategy is a procedure which language users employ in the production or comprehension of language. For example, a speaker of English might adopt the strategy that when he encounters an auxiliary verb before the subject of a sentence, that utterance may well be an intended question of a certain sort, as in the example cited above. Furthermore, the strategies utilized in production need not necessarily be those utilized in comprehension. (It may be noted that all of the strategies to be discussed in this paper relate to comprehension rather than production, although a reformulation in terms of production would not be particularly difficult in this area. Basically, production strategies must honor hearer expectations.) An important aspect of the distinction between a cognitive strategy and a rule of grammar is that the strategy, as a procedure, is often language-independent, while a rule of grammar is by definition language specific. However, for a strategy to be employed, it must necessarily interact with the particulars of a given grammar, and it is this interaction of strategy with grammatical structure which has engendered a great deal of confusion within the research literature.

Although the notion of cognitive strategies is fairly widely accepted, the details of the strategies, their relative organization, and their interactions are not at all well understood. In order to address this issue in a tractable fashion, the domain of English relative clause structures is singled out here for special attention, for the following reasons : (1) Those strategies operative for simplex sentences must, to a large extent, also be operative in complex sentences; (2) English sentences containing relative clauses provide an extensive but manageable set of structures for experimental investigation since English allows relative clauses to be attached to NPs playing virtually any grammatical role; (3) Almost any NP within a relative clause can be a relative pronoun; (4) The strategies proposed for relative clause processing are diverse and often conflicting in their predictions and interpretations.

When the literature dealing with cognitive strategies is reviewed, a great many different proposals are encountered, although a few fundamental strategies appear to lie at the heart of, and often subsume, most of the more specific proposals. These general strategies are of two kinds, those involved in processing individual sentences and those involved in the organization of discourse. The sentence processing strategies are the following : 
THE CLOSURE STRATEGY. In processing a particular unit (clause, phrase, etc.), the hearer attempts to obtain closure (i.e., syntactic or semantic integration) at the earliest possible point.

THE NORMAL FORM STRATEGY. The hearer assumes that the unit being processed is in its "normal" or "canonical" form (for that specific language) unless it is overtly marked to the contrary.

THE NON-AMBIGUITY STRATEGY. The hearer assumes that the unit which he is processing is not ambiguous. (That is, while alternative readings of lexical items or larger constituents may be possible, the hearer assumes that the most likely reading in the given context is the intended reading.)

THE BRACKETING STRATEGY. The hearer expects that when a new unit for processing is encountered, it will be marked as such.

Since these strategies are relatively general, it is useful to spell out in some detail the empirical consequences and predictions associated with each, and the effect on the hearer when the strategy fails, or the effect on the speaker if he subsequently realizes the possibility of failure relative to his intended message.

CLOSURE is one of the best known strategies, associated with a wide range of cognitive processes other than language processing. Specifically, it suggests that the hearer expects to "complete" as quickly as possible the unit being processed (i.e., apprehend the meaning in its current context), where the unit may be a clause, with its associated semantic proposition, or a phrase, such as a NP. The strategy predicts that those structures in which closure is interrupted or delayed should be relatively more difficult to process than those in which no interruption takes place. This strategy interacts with the grammatical properties of languages in different ways. English, for example, is an SVO language with relative clauses following the NP being modified, while Japanese is an SOV language, and its relative clauses precede the modified NP. Consequently, the CLOSURE strategy predicts that an English sentence which has a relative clause attached to its final NP, such as "The man saw the thief who stole the briefcase", should be easier to process than one which has the relative clause attached to its subject NP, as "The thief who stole the briefcase saw the man". That is, it predicts that in English, a sentence with a relative clause on the subject NP is harder to process than a sentence with a relative clause on the (final) object NP. For Japanese, however, the CLOSURE strategy predicts that a sentence with the relative clause on the subject NP should be easier to process than one with the relative clause on the (internal) direct object NP, since the former does not interrupt the main clause. The heuristic involved here is simply "finish up one thing before starting another".

The NORMAL FORM strategy suggests that the hearer expects a processing unit to be in its "typical" or "canonical" form. It is important here to recognize that this strategy can refer to either a syntactic form (e.g., the expected word order) or the expected order of semantic roles in a sentence. For example, the normal form for English clauses is $\mathrm{SV}(\mathrm{O})$. However, a relative clause can be in the form SVO, as "the man who saw the thief", or in the form OSV, as in "the man whom the thief saw". The NORMAL FORM strategy predicts that the former, being closer to the basic word order, should be easier to process than the latter. Moreover, the normal order of semantic roles in a simple clause is typically actor-verb-patient, as in "The man kicked the ball." However, there are sentences in which this order is violated, as in such passives as "The ball was kicked by the man." In isolation, then, the expectation is that the active form, since it adheres to the normal order of semantic roles, should be easier to process than the passive.

The importance of the clause as a processing unit is crucial to the viability of both the CLOSURE and NORMAL FORM strategies. The evidence in support of the "psy- 
chological reality" of clauses as processing units is extensive (see, e.g., Garrett, Bever \& Fodor 1966 ; Fodor, Bever \& Garrett 1974 ; Hurtig 1978 ; Chapin, Smith \& Abrahamson 1972), while the integrity of the clause as a basic unit is itself reflected in Bever's (1970b) proposed Strategies A through D, which state :

STRATEGY A. Segment together any sequence X...Y, in which the members could be related by primary internal structural [e.g., semantic] relations "actor action object... modifier" (p. 290).

STRATEGY B. The first N...V...(N)... clause (isolated by Strategy A) is the main clause, unless the verb is marked as subordinate (p. 294).

STRATEGY C. Constituents are functionally related internally according to semantic constraints (p. 296).

STRATEGY D. Any Noun-Verb-Noun (NVN) sequence within a potential internal unit in the surface structure corresponds to "actor-action-object" (p. 298).

Strategies B and D depend overtly on English word order and are therefore language specific. Similarly, Strategies A and D rely on the typical order of semantic roles in English and are also language specific, while Strategy $\mathrm{C}$ is semantically based but language independent. Thus, even in these relatively plausible proposals, syntactic and semantic aspects are interwoven with language specific and language independent properties. Taken together, these four strategies are subsumed by the more general CLOSURE and NORMAL FORM strategies cited above, although Bever's proposals are, with the exception of Strategy $\mathrm{C}$, tied to language-specific factors.

Bever (1970a) reviews the empirical evidence in support of each of the strategies. Strategy A is alleged to be supported by certain of the click studies (e.g., Fodor \& Bever 1965 ; Bever, Lackner \& Kirk 1969 ; Bever, Lackner \& Stolz 1969). While the integrity of surface clauses is supported by those studies, certain other conclusions drawn there have been severely criticized (cf. Reber \& Anderson 1970). Strategy B is supported by Clark and Clark (1968), who showed that a sentence is relatively harder to memorize if a subordinate clause precedes the main clause, than if the order is reversed. Strategies $A$ and $\mathrm{C}$ are both subsumed by CLOSURE, while $\mathrm{A}, \mathrm{B}$, and D reflect syntactic and semantic aspects of NORMAL FORM. Bever's four strategies can thus be seen as derivable from the more general strategies cited above.

In his research dealing with language acquisition, Slobin (1973) proposed several "operating principles" which, he claims, guide language acquisition. One of the most important of these suggests that, at an early stage, children avoid structures which contain interruptions or deviations from normal order. This principle clearly involves both CLOSURE and NORMAL FORM. However, the issue of precisely what constitutes the "normal" or "canonical" word order is of extreme importance, since any version of the NORMAL FORM strategy could be rendered vacuous simply by defining as normal that order which is easiest to comprehend. What is needed, then, is an independent way of determining the normal word order for a language. Givon (1979) has suggested just such an approach, arguing that the normal word order for a language is represented in the simple affirmative, declarative sentence, the least "marked" and the presuppositionally least burdened type. This proposal accords with the familiar approach taken, e.g., by Greenberg (1963), and it further supports the correspondence between normal word order and "kernel" sentential structure in a variety of languages. Considerable evidence has been offered in support of the NORMAL FORM strategy in the areas of language acquisition (Slobin 1966, 1973, 1979 ; Brown 1971 ; Sheldon 1974 ; Prideaux 1979a ; Lykowsky 1980 ; Kawashima 1980; Harada et al. : 1976), and some evidence has also been offered for its viability in adult language processing (cf. Fodor, Bever \& 
Garrett 1974 ; Prideaux 1980). Further support for CLOSURE comes from the observation that passives tend to be harder to comprehend than actives, and that at certain ages, children tend to interpret reversible passives as actives (Slobin 1966). Savin and Perchonock (1965) provide similar supporting evidence.

Townsend, Ottaviano, and Bever (1979), using a probe-latency technique on both children and adults, found that for complex sentences, latencies were shorter for subordinate than for main clauses, regardless of the position of the subordinate clause. They concluded that the main clause is interpreted sooner than the subordinate clause. The stimuli included coordinate and comparative sentences, plus two types of complex sentences, namely those with two clauses differing in temporal order (e.g., before, and after sentences) and sentences containing relative clauses. In the latter group, only two types of relative clause structures were employed, those in which the relative clause interrupted the main clause, which Townsend et al. treated as having the main clause after the subordinate one, and those in which the relative clause followed the main clause, which they interpreted as having main clause first. They found that when dealing with relative clause structures, adults processed non-interrupted clauses faster than interrupted ones, and that clauses with normal word order are faster than those with non-normal order. Their results, therefore, support the viability of both the CLOSURE and NORMAL FORM strategies. The NON-AMBIGUITY strategy can also refer to either syntactic or semantic factors. Typically, of course, "ambiguity" refers to semantic matters, but ambiguity may arise for syntactic reasons. For example, in a familiar sentence like "Sam called Suzie a taxi", the hearer normally expects the sequence of two NPs after a transitive verb to be analyzed as the indirect object followed by the direct object, as in "Sam bought Suzie a flower." However, there are syntactic sequences of the form $\mathrm{Vt}+\mathrm{NP}+\mathrm{NP}$ which can be analysed in more than one way, as in the former case. The NON-AMBIGUITY strategy suggests that sentences which can be analyzed in more than one way, and where the alternatives are not contextually controlled, should be more difficult to process than those for which only one syntactic analysis is possible.

The semantic aspects of the NON-AMBIGUITY strategy predict that if the semantic properties of the verb and its NP arguments allow only one possible semantic role for each NP, the clause should be easier to comprehend than if more than one assignment for each NP is possible. A verb and its NP arguments can be designated as a "predication", represented as $\mathrm{V}(\mathrm{X}, \mathrm{Y})$, where $\mathrm{X}$ and $\mathrm{Y}$ are the NPs occurring with the $V$. For a predication such as follow (the cow, the horse), either the cow or the horse can function as subject, and in this case the NPs are "reversible" since the semantics of follow do not impose a unique grammatical assignment on the NP arguments. However, for a predication like eat (the dog, the cookie), the semantics involved forces an assignment of the dog as subject, and this predication is "non-reversible." This strategy was supported by Slobin (1966), who found that non-reversible passives are no harder to verify than the corresponding actives, as in the pair "The cookie was eaton by the dog" and "The dog ate the cookie." However, for reversible pairs such as "The horse was followed by the cow" and "The cow followed the horse", the passive took longer to verify. Mehler and Carey (1968) offered further support, using a picture identification task. The strategy therefore predicts that a relative clause like "the cookie (which) the dog ate" should be easier to comprehend than "the cow (which) the horse followed". Picture identification tasks, however, are somewhat suspect, since subject responses might be based on a verification strategy as well as on strategy under investigation. Relatively few picture verification tasks are now employed in such research.

Finally, the BRACKETING strategy, the fourth in our list of general procedures, indicates that the hearer is looking for an indication of the beginning of a new unit to 
process. If, for example, he encounter a sentence with an initial before or after, he expects a subordinate clause or phrase, whereas if he has no indication to the contrary, he expects the normal form. In processing a sentence such as "The man the dog bit fled", the absence of a relative pronoun in the relative clause introduces a possible ambiguity until the first vers is encountered, since two contiguous NPs in English can be conjoined, as in "The man, the dog, and the cat all fled." However, if the relative pronoun whom or that appears after the man, this indicates a BRACKETING for the beginning of a new unit.

The BRACKETING strategy suggests that various devices are employed for the identification of new processing units. Relative clauses are typical instances of such units, and their boundaries are marked in various ways in different languages. Bever (1970a) proposed two strategies directly relevant for English sentences containing relative clauses, namely :

STRATEGY J. In ... NP1 NP2(VP) ... sequence in the external structure, NP1 is the internal object of an internal structure sentence unit which NP2 is the subject (p. 337).

STRATEGY K. In ... V1 V2 ... (in which the verbs are finite), V2 corresponds to the main verb of a sentence with $\mathrm{V} 1$ as the subordinate verb (p. 337).

Both of these strategies relate to sentences containing relative clauses, both are language specific, and both refer to both syntactic structure and grammatical functions. For a sentence like "The man the dog bit quickly ran away", STRATEGY J predicts that the first of two consecutive NPs, the man, will be interpreted as the object of the verb bit (e.g., the $\operatorname{man}=O\left(\right.$ bite), while the dog, will be interpreted as the subject ${ }^{1}$. This strategy is important for those relative clauses in which the relative pronoun is absent, since a sequence of two contiguous NPs can also function as coordinate NPs, as in "The man, the dog, and the cat all fled." STRATEGY $\mathbf{J}$ is, in fact, a revision of an earlier proposal by Fodor and Garrett (1967), namely :

THE NP RP NP STRATEGY. Given the sequence NP1 RP NP2, assume the NPs are related to each other as object and subject respectively of the same verb.

This strategy, along with $\mathbf{J}$, provides a functional assignment for each of two consecutive NPs, whether they are separated by a relative pronoun (RP) or not.

Strategy $\mathbf{J}$ taken together with the NP RP NP strategy constitute a special case of the NON-AMBIGUITY strategy and predict that a clause without a relative pronoun will be more difficult to process than one with a relative pronoun. This prediction has received strong empirical support (cf. Bever : 1970a). Similarly, STRATEGY K states that when two finite verbs are contiguous, the first is a part of the embedded clause, and the second is the main verb. This strategy applies to sentences containing interrupting relative clauses, such as "The man (whom) the dog bit fled", where the first verb is correctly assigned to a subordinate clause and the second to a superordinate clause. These syntactically based parsing strategies are similar to that offered by Clark and Clark (1977) who, following Kimball (1973), proposed a very simple strategy for initiating relative clauses in parsing, namely :

1. Hereafter the following notation will be used to indicate functional relations obtaining between a predicate (a verb or adjective) and its arguments (usually NPs) : $x=G R(y)$, where $x$ is some NP which bears the grammatical relation $G R$ to the predicate $y$. The grammatical relations include $S\left(\right.$ subject $\left.{ }^{\prime \prime}\right), O$ ("object"), M ("modifier"), etc. The predicates will be specified in their full (non-tensed) forms. Thus, the $\operatorname{man}=O($ bite $)$ is read as "the man is the object of the predicate (verb) bite." 
THE RC IDENTIFICATION STRATEGY. Whenever a relative pronoun is encountered, begin a new clause (Clark \& Clark : 1977, p. 59).

This strategy makes no differential prediction as to relative difficulty, but rather expresses a special, language-specific case of BRACKETING.

One of the more influential proposals for dealing with the acquisition of sentences containing relatives clauses is Sheldon's (1974) PARALLEL FUNCTION hypothesis. This strategy was proposed to account for experimental results which, she claimed, could not be accounted for by either the NORMAL FORM or the CLOSURE strategies. Like other strategies associated with language acquisition studies, this one can be expressed as a hypothesis about the relative ease or difficulty of language comprehension as well as acquisition. Accordingly, the strategy can be formulated as :

THE PARALLEL FUNCTION STRATEGY. Comprehension for sentences containing relatives clauses is facilitated if the relative pronoun plays the same grammatical role (subject or object) as is played by the modified noun.

Although Sheldon $(1974,1977)$ has vigorously championed the PARALLEL FUNCTION strategy, others have challenged it on three separate accounts. First, it has been suggested that Sheldon's data can be readily reanalyzed in terms of various word order hypotheses, suggesting that it is a pattern of sentence conjunction and not parallel function which facilitates the earlier acquisition of certain relative clause structure (see, e.g., Tavakolian : 1977 and Prideaux : 1979a for details). Secondly, the PARALLEL FUNCTION strategy has been criticized on the grounds that other researchers have not been able to replicate Sheldon's results (see Bowerman : 1979 for a review). Finally, in Prideaux (1979a) it is argued that the PARALLEL FUNCTION strategy has no real explanatory power. This strategy is syntactic, at least to the extent that it must access such categories as subject and object, although it does not depend on word order. That is, it appears to be a language independent, grammatical strategy, with no semantic or discourse component. Moreover, its viability in adult language comprehension is questionable, and even Sheldon (1977) failed to find strong evidence for is in adult performance.

In comparing children's and adults' comprehension of relative clauses, Sheldon (1977) proposed the following purely syntactic parsing strategy to account for the results of her adult subjects :

THE ADJACENCY STRATEGY. In parsing a noncompound sentence, start from the left and group together as constituents of the same clause two adjacent NPs (i.e., those not separated by another NP) and an adjacent verb not already assigned to a clause. Interpret the first NP as the subject and the second NP as the object of the verb (Sheldon : 1977).

The strategy applies blindly from left to right, ignoring clause boundaries and assigning a surface grammatical role (subject or object) to each full NP it encounters, deliberately ignoring relative pronouns. As Sheldon noted, the strategy sometimes fails to assign grammatical roles correctly. For example, in a sentence such as "The man who caught the thief received the reward", the strategy correctly assigns the man $=S($ catch $)$ and the thief $=O($ catch $)$. It then skips over the relative pronoun who and incorrectly assigns the thief $=S$ (receive) and the reward $=O$ (receive). Thus, the ADJACENCY strategy makes on error for this type of sentence. Sheldon proposed that the number of errors made by the strategy determines the relative processing difficulty for that type of structure, with her adult data providing supporting evidence in that the number of errors made by the strategy corresponded to the rank ordering of difficulty or her results. Sherldon's results 
have not, to our knowledge, been replicated, although when tested against naturalness data, the ADJACENCY strategy failed (Prideaux : 1980).

There are, in addition to the sentence processing strategies mentioned above, strategies which relate to the structure of discourse. Perhaps the best known of these is the GIVEN-NEW strategy, which might be added as a fifth member to our set. It can be formulated as follows :

THE GIVEN-NEW STRATEGY. Once the context of a discourse has been established, the hearer expects that Given information will normally be separated from New information in a systematic way. Typically, Given information precedes New information, but when New information precedes Given, special grammatical devices are used to signal the non-typical ordering of New-Given.

This strategy, unlike the four mentioned above, relates to the distribution of information within a discourse. In fact, while the order Given-New is the typical, unmarked order for English and many other languages, some languages employ the reverse order as typical. The universl characteristic of this strategy lies in the separation of the two general types of information. Given information is that which the speaker assumes he shares with the listener, while New information is that which the speaker assumes the hearer is not aware of. The speaker, then, arranges his discourse and the structure of his sentences to meet this expectation. In English, the hearer's expectation is that one component, e.g., the Given, will precede the New. Not only is this strategy operative in the organization of discourse, but it is also operative to some extent within sentences. For example, there are some potential instances within sentences of "free" ordering, as in the case of direct and indirect objects. However, if one of the object NPs is Given and the other is New, the Given NP typically precedes the New, unless special devices are employed to indicate the non-typical ordering. For example, in response to the question "Who did you send the card to ?", appropriate responses might include "to Sue", or "I sent it to Sue". However, responses such as "a card", or "I sent to her a card" would be quite inappropriate, not because there are not acceptable English utterances but rather because the question establishes card as Given. Accordingly, since Given information normally precedes New, those potential responses which violate the Given-New Strategy render them inappropriate.

The GIVEN-NEW strategy reflects similar proposals made by Halliday (1967a, $1967 \mathrm{~b}, 1968)$ and Chafe $(1970,1972)$, among others, and a great deal of evidence has been accumulated in support of it. A review of much of the early empirical support is found in Clark and Haviland (1974) and Clark and Clark (1977). Smyth, Prideaux, and Hogan (1979) demonstrated that the GIVEN-NEW strategy is responsible for the relative ordering of direct and indirect objects when they differ in "Givenness." Givon (1979) has argued that in simple declarative sentences with subjects and direct objects, the subject NP is typically definite and Given, while the direct object is Given only about half of the time, although an indefinite direct object is typically New, and definite direct object is typically Given. Thus, a sentence like "The policeman caught a thief" is typically viewed as having a Given subject and a New direct object, while in "The policeman caught the thief" both the subject and object are treated as Given.

It should be noted that the GIVEN-NEW strategy is not tied exclusively to the grammatical properties of English (see, e.g., Takahara : 1978 and Prideaux : 1982, for evidence that the strategy is operative in Japanese). Of course, as a discourse strategy, its salience may only be apparent for sentences in discourses, and not in isolation. Accordingly, it is an empirical question whether or not the GIVEN-NEW strategy will emerge as important for sentences in isolation. 
Most of the strategies discussed above can be subsumed, then, under the aegis of five general strategies. The only ones which cannot are Sheldon's PARALLEL FUNCTION and ADJACENCY strategies, and even ADJACENCY, to some extent, appears to be a consequence of the NORMAL FORM strategy since it employs expected word order for English. One important conclusion to be drawn from the above discussion is that many of the particular strategies found in the literature are actually composite statements, with one part derived from a very general strategy, such as CLOSURE, and the other part derived from the grammatical properties of the language under investigation. Bever's (1970a) strategies A and D, for example, involve both the languagespecific properties of English word order, coupled with the more general principles of CLOSURE and NORMAL FORM. It is just this infelicitous mixture that has confounded a great deal of research in the area. Of course, it must be made clear that a general cognitive strategy cannot be examined in isolation. It must be tested in the context of a given linguistic structure. Nevertheless, the evidence adduced in favor of a kind of "mixed" strategy must be considered in terms of a general strategy interacting with the structural properties of a given language.

In summary, it has been argued that a clear conceptual distinction must be drawn between a cognitive strategy as a language-independent psychological process on the one hand, and a language-specific grammatical rule or structure on the other. It has also been argued that once this distinction is drawn, many of the candidate strategies found in the recent psycholinguistic literature can be recognized as having confounded these two components, and once the confounding is eliminated, most such proposals are reducible to a small set of very general processing strategies. Finally, a natural suggestion which arises from this analysis of the cognitive strategies paradigm is that the basic strategies (e.g., CLOSURE, NORMAL FORM, GIVEN-NEW, etc.) are potentially universal in character by virtue of arising in the human cognitive system.

\section{REFERENCES}

BEVER, T.G. (1970a) : "The Cognitive Basis for Linguistic Structures", in J.R. HAYES (Edit.), Cognitive and the Development of Language, New York, Wiley.

BEVER, T.G. (1970b) : "The Influence of Speech Performance on Linguistic Structure", in G.B. FLORES D'ARCAIS \& W.J.M. LEVELT (Edits), Advances in Psycholinguistics, Amsterdam, North-Holland.

BEVER, T.G., J. LACKNER \& R. KIRK (1969) : "The Underlying Structure Sentence is the Primary Unit of Speech Perception", Perception and Psychophysics, 5, pp. 225-234.

BEVER, T.G., J. LACKNER \& W. STOLZ (1969): "Transitional Probability is not a General Mechanism for the Segmentation of Speech", Journal of Experimental Psychology, 79, pp. 387-394.

BOWERMAN, M. (1979): "The Acquisition of Complex Sentences", in P. FLETCHER \& M. GARMAN (Edits), Language Acquisition, Cambridge, Cambridge University Press.

BROWN, H.D. (1971) : "Children's Comprehension of Relativized English Sentences", Child Development, 42, pp. 1923-1926.

CHAFE, W.L. (1970) : Meaning and the Structure of Language, Chicago, University of Chicago Press.

CHAFE, W.L. (1972) : "Discourse Structure and Human Knowledge", in J.B. CARROLL \& R.O. FREEDLE (Edits), Language Comprehension and the Acquisition of Knowledge, Washington, D.C.

CHAPIN, P.G., T.S. SMITH \& A.A. ABRAHAMSON (1972) : "Two Factors in Perceptual Segmentation of Speech", Journal of Verbal Leaming and Verbal Behavior, 11, pp. 164-173.

CLARK, H.H. \& E.V. CLARK (1968) : "Semantic Distinctions and Memory for Complex Sentences", Quarterly Journal of Experimental Psychology, 20, pp. 129-138.

CLARK, H.H. \& E.V. CLARK (1977) : Psychology and Language : An Introduction to Psycholinguistics, New York, Harcourt Brace Jovanovich.

CLARK, H.H. \& S.E. HAVILAND (1974) : "Psychological Processes as Linguistic Explanation", in D. COHEN (Edit.), Explaining Linguistic Phenomena, Washington, Hemisphere.

FODOR, J.A. \& T.G. BEVER (1965) : "The Psychological Reality of Linguistic Segments", Journal of Verbal Learning and Verbal Behavior, 4, pp. 414-420.

FODOR, J.A., T.G. BEVER \& M. GARRETT (1974) : The Psychology of Language : An Introduction to Psycholinguistics and Generative Grammar, New York, McGraw-Hill 
FODOR, J.A. \& M. GARRETT (1967) : "Some Syntactic Determinants of Sentential Complexity", Perception and Psychophysics, 2, pp. 289-296.

GARRETT, M., T. BEVER \& J. FODOR (1966): "The Active Use of Grammar in Speech Perception", Perception and Psychophysics, 1, pp. 30-32.

GIVON, T. (1979) : On Understanding Grammar, New York, Academic Press.

GREENBERG, J.H. (Edit.) (1963) : Universals of Language, Cambridge, Mass., MIT Press.

HALLIDAY, M.A.K. (1967a) : Notes on Transitivity and Theme in English : I", Journal of Linguistics, 3, pp. $37-81$.

HALLIDAY, M.A.K. (1967b) : "Notes on Transitivity and Theme in English : II", Journal of Linguistics, 3, pp. 199-244.

HALLIDAY, M.A.K. (1968) : "Notes on Transitivity and Theme in English : III", Journal of Linguistics, 4, pp. 179-215.

HARADA, S.I., T. UENO, H. HAYASHIBE \& H. YAMADA (1976) : "On the Development of Perceptual Strategies in Children : A Case Study on the Japanese Child's Comprehension of Relative Clause Constructions", Annual Bulletin RILP, 10, pp. 199-224.

HURTIG, R. (1978): "The Validity of Clausal Processing Strategies at this Discourse Level", Discourse Processes, 1, pp. 195-202.

KAWASHIMA, M. (1980) : The Acquisition of Japanese Relative Clauses, unpublished M.Sc. thesis, University of Alberta.

KIMBALL, J.P. (1973) : "Seven Principles of Surface Structure Parsing in Natural Language", Cognition, 2, pp. $15-47$

LAKOFF, G. \& H. THOMPSON (1975) : "Introducing Cognitive Grammar", in C. COGEN, H. THOMPSON, G. THURGOOD, K. WHISTLER \& J. WRIGHT (Edits), Proceedings of the First Annual Meeting of the Berkeley Linguistics Saciety, Berkeley, California, Berkeley Linguistics Society, pp. 295-313.

LYNKOWSKY, P.E. (1980) : Development of Relative Clauses : Comprehension Strategies in English and Ukrainian, unpublished Ph.D. thesis, University of Alberta.

MEHLER, J. \& P. CAREY (1968): "The Interaction of Veracity and Syntax in the Processing of Sentences", Perception and Psychophysics, 3, pp. 109-111.

PRIDEAUX, G.D. (1979a): "The Acquisition of Relative Clauses : A Functional Analysis", Canadian Journal of Linguistics, 24, pp. 25-40.

PRIDEAUX, G.D. (1980) : "The Role of Perceptual Strategies in the Processing of English Relative Clause Structures", in Proceedings of the Eighth International Conference on Computational Linguistics, Tokyo, pp. 60-66.

PRIDEAUX, G.D. (1982) : "The Processing of Japanese Relative Clauses", Canadian Journal of Linguistics, 27, pp. 23-30.

SAVIN, H. \& E. PERCHONOCK (1965) : "Grammatical Structure and the Immediate Recall of English Sentences", Journal of Verbal Learning and Verbal Behavior, 4, pp. 348-353.

REBER, A.S. \& J.R. ANDERSON (1970) : "The Perception of Clicks in Linguistics and Nonlinguistic Messages", Perception and Psychophysics, 8, pp. 81-89.

SHELDON, A. (1974) : "The Role of parallel Function in the Acquisition of Relative Clauses in English", Journal of Verbal Learning and Verbal Behavior, 13, pp. 272-281.

SHELDON, A. (1977) : "On Strategies for Processing Relative Clauses : A Comparison of Children and Adults", Journal of Psycholinguistic Research, 6, pp. 305-318.

SLOBIN, D.I. (1966) : "Grammatical Transformations and Sentence Comprehension in Child and Adulthood", Journal of Verbal Learning and Verbal Behavior, 5, pp. 219-227.

SLOBIN, D.I. (1970) : "Universals of Grammatical Development in Children", in G.B. FLORES D'ARCAIS \& W.J.M. LEVELT (Edits), Advances in Psycholinguistics, Amsterdam, North-Holland.

SLOBIN, D.I. (1973) : "Cognitive Prerequisite for the Development of Language", in C.A. FERGUSON \& D.I. SLOBIN (Edits), Studies of Child Language Development, New York, Holt, Rinehart \& Winston.

SLOBIN, D.I. (1979) : Psycholinguistics (2nd ed.), Glenview, Ill., Scott Foresman.

SMYTH, R.H., G.D. PRIDEAUX \& J.T. HOGAN (1979) : "The Effect of Context on Dative Position", Lingua, 47, pp. 27-42.

TAKAHARA, P.O. (1978) : "Pragmatic Functions of the Given/new Contract in Child Discourse", Language Sciences, 1, pp. 244-272.

TAVAKOLIAN, S.L. (1977) : Structure and Function in Child Language, unpublished Ph.D. thesis, University of Massachusetts, Amherst.

TOWNSEND, D.J., D. OTTAVIANO \& T.G. BEVER (1979) : "Immediate Recall for Words from Main and Subordinate Clauses at Different Age Levels", Journal of Psycholinguistic Research, 8, pp. 83-101. 